\title{
TIMAEUS' EXPLANATION OF SENSE-PERCEPTUAL PLEASURE
}

\author{
DAVID WOLFSDORF \\ Temple University*
}

\begin{abstract}
Much has been written about Plato's accounts of pleasure in Republic 9 and Philebus, almost nothing about his account in Timaeus. But with respect to sense-perceptual pleasure specifically, the account in Timaeus is unique and extremely informative. This paper examines, in turn, the physiology and the psychology of sense-perceptual pleasure, focusing on the text at $64 \mathrm{a} 2-65 \mathrm{~b} 3$, but drawing on a wide range of passages from elsewhere in the dialogue. The paper concludes with a further suggestion: that Timaeus is committed to an implicit distinction between two kinds of perceptual pleasure, sense-perceptual pleasure and 'brute' pleasure.
\end{abstract}

Keywords: [add up to five keywords separated by commas]

[Please note that the references have all been edited for house-style; in particular, the publisher has been replaced by the place of publication. Thus, all references should be checked by the author]

\section{Introduction}

Much has been written about Plato's accounts of pleasure in Republic 9 and Philebus, almost nothing about his account in Timaeus. ${ }^{1}$ But at least with respect to bodily pleasure, the Timaeus account is extremely informative. These two points justify an examination. Since the character Timaeus of Locri presents the account and characterizes it as of aitíal, this paper's broad aim is to clarify Timaeus' explanation. ${ }^{2}$ The kind of bodily pleasure Timaeus explains is sense-perceptual pleasure; hence, the title.

Timaeus' explanation is largely confined to $64 \mathrm{a} 2-65 \mathrm{~b} 3$. This passage falls within a larger movement of the dialogue, 61c3-68d7, which immediately follows Timaeus' account of the material elements and compounds. He begins the larger movement with these words:

\footnotetext{
*dwolfsdo@temple.edu.

1 Two small exceptions are: J.C.B. Gosling and C.C.W. Taylor, The Greeks on Pleasure (Oxford 1982) 178-83; D.C. Russell, Plato on Pleasure and the Good Life (Oxford 2005) 229-37. On perception and sensation in Timaeus generally, see D. O'Brien, Theories of Weight in the Ancient World: Plato Weight and Sensation 2 (Leiden 1984) 107-43; L. Brisson, 'Perception sensible et raison dans le Timée', in T. Calvo and L. Brisson (eds), Interpreting the Timaeus-Critias: Proceedings of the IV Symposium Platonicum (Sankt Augustin 1997) 307-16; U. Hirsch, 'Sinnesqualitäten und ihren Namen', in Calvo and Brisson (n.1) 317-24; D. O'Brien, 'Perception et intelligence dans le Timêe', in Calvo and Brisson (n.1) 291-305; L. Brisson, 'Plato's theory of sense perception in the Timaeus: how it works and what it means', Proceedings of the Boston Area Colloquium in Ancient Philosophy 12 (1998) 147-74; J.-F. Pradeau, 'L'âme et la moelle: Les conditions psychiques et physiologiques de l'anthropologie dans le Timée de Platon', Archives de Philosophie 61 (1998) 489-518; A. Barker, 'Timaeus on music and the liver', in M.R. Wright (ed.), Reason and
}

Necessity: Essays on Timaeus (Swansea 2001) 85-99; T. Ganson, 'The Platonic approach to sense-perception', HPhQ 22 (2005) 1-15; K. Ierodiakonou, 'Plato's theory of colours in the Timaeus', Rhizai 2 (2005) 219-33; F. Karfík, 'What the mortal parts of the soul really are', Rhizai 2 (2005) 197-217; P. Lautner, 'The Timaeus on sounds and hearing with some implications for Plato's general account of sense-perception', Rhizai 2 (2005) 235-53. Cf. also the editions of R.D. Archer-Hind, Timaeus of Plato (London 1888); A.E. Taylor, $A$ Commentary of Plato's Timaeus (Oxford 1928); F.M. Cornford, Plato's Cosmology (London 1935, (reprinted Indianapolis 1997). T. Johansen, 'Body, soul, and tripartition in Plato's Timaeus', OSAPh (2000) 87-111 and Plato's Natural Philosophy (Oxford 2004) are helpful generally.

${ }^{2}$ I take $\alpha i \tau i ́ \alpha$ and its cognates to be ambiguous between explanation and cause, where a cause is that which is explained. Moreover, I understand 'cause' broadly to include, but not be limited to, so-called efficient cause. 
We have ... presented the various kinds [of material elements and compounds], variegated in their shapes, in terms of their combinations and transformations into one another. We must now try to clarify through what causes ( $\left.\alpha i \tau^{\prime} \alpha 1\right)$ their affections $(\pi \alpha \theta \eta \dot{\mu} \alpha \tau \alpha)$ [that is, how they affect us] have come into existence. To begin with, perception ( $\alpha$ i $\sigma \theta \eta \sigma \iota v$ ) must belong to those things that are said to be eternal. Yet we have not discussed how flesh and related [bodily parts] are generated, nor the part of the psyche that is mortal $(\theta v \eta \tau o ́ v)$. But we cannot adequately discuss the perceptual affections $(\pi \alpha \theta \eta \dot{\mu} \alpha \tau \alpha \ldots \alpha i \sigma \theta \eta \tau \imath \kappa \alpha ́)$ without these. On the other hand, it is impossible to discuss both simultaneously. So we must first assume the one and return to discuss the other. Therefore, assume that we have the requisite bodily and psychic entities. $^{3}$

The larger movement at $61 \mathrm{c} 3-68 \mathrm{~d} 7$ is, then, devoted to explaining the affections $(\pi \alpha \theta \eta \dot{\eta} \mu \alpha \tau)$ of the material elements and compounds. Timaeus refers specifically to perceptual ( $\alpha i \sigma \theta \eta \tau \imath \kappa \alpha$ ) affections. Thus, he endeavours to explain the effects that the material elements and compounds have on percipient beings.

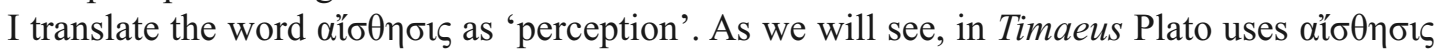
in a narrower sense than 'perception'. The English word can refer to an act of cognition that solely involves the mind. For example, one can perceive (or see) the correct answer to a problem. More often, 'perception' refers to sense-perception, that is, perception by one of the five classical sensory organs or faculties. Plato uses al̋ $\theta \eta \sigma ı \varsigma$ in both ways within his corpus. But in Timaeus he understands $\alpha \grave{\imath} \sigma \theta \eta \sigma ı \varsigma$ precisely as a somatic-cum-psychic cognitive process. Sense-perception is the

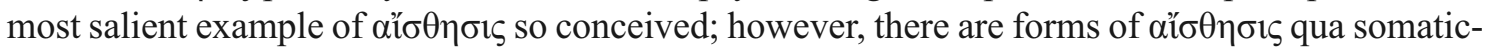
cum-psychic cognition independent of the classical sense-perceptual faculties, for example percep-

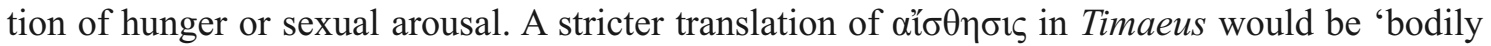
perception'. Still, I use 'perception' for convenience.

Timaeus understands perceptual affections, then, to be somatic effects that percipient bodies undergo and that are transmitted to the psyches of those percipient bodies. Note that the entity affecting the percipient body may be external or internal to the percipient body. For example, consider forms of proprioception arising through torn muscles or headaches. Timaeus does not overlook such conditions, and I see no evidence that Plato restricts alo $\theta \eta \sigma ı \varsigma$ to exteroception. ${ }^{4}$

Since Timaeus understands perceptual affections as somatic-cum-psychic processes, he states that an adequate explanation of perceptual affections must include an explanation of the flesh and related bodily parts as well as of the mortal part of the psyche. But this is too much to explain at once. So Timaeus postpones the explanation of the mortal psyche (at 69c5-72d8) until he has completed his initial explanation of the perceptual affections. Subsequently (at 72e1-81e5), he explains flesh and related bodily parts.

At $64 \mathrm{a} 2-65 \mathrm{~b} 3$, then, Timaeus explains pleasure in the context of explaining perceptual affections. He does so precisely, as he says, because pleasure occurs within ( $\dot{\varepsilon} v)$ and attends upon ( $\dot{\varepsilon} \pi \mathrm{o} \mu \dot{\varepsilon} v \alpha \varsigma)$ other perceptual affections. Actually, Timaeus here explains affections of the five classical sense-perceptual faculties, that is, sense-perceptual affections. Hence, he is claiming that pleasure occurs within and attends upon sight, hearing and so forth. Consequently, I will refer to the pleasure that Timaeus here explains as 'sense-perceptual pleasure'.

Section II focuses on the physiology, that is, the somatic conditions, that sense-perceptual pleasure involves. Section III turns to the psychology of sense-perceptual pleasure; it examines the parts of the psyche that sense-perceptual pleasure involves and the roles these parts play. Section IV is motivated by the following point: certain pleasures relating to nutrition, hydration and sex, which also involve somatic-cum-psychic processes and which feature elsewhere in Plato's corpus, including elsewhere in Timaeus, are absent from Timaeus' explanation at 64a2-65b3.

\footnotetext{
${ }^{3}$ Ti. 61c3-d5 (hereafter all Stephanus pages refer to Timaeus, unless explicitly expressed otherwise.)
}

\footnotetext{
${ }^{4}$ For discussion of Plato's conception of $\pi \alpha \theta \dot{\eta} \mu \alpha \tau \alpha$ in Timaeus generally, see O'Brien (n.1) 124-43.
} 
Section IV considers this fact and concludes by suggesting that Timaeus operates with an implicit distinction between two kinds of bodily, that is, perceptual pleasure: sense-perceptual pleasure and what I call 'brute' pleasure.

\section{The physiology of sense-perceptual pleasure}

Timaeus' discussion of perceptual affections is divisible as follows: introduction (61c2-d5), explanation of the cause of pansomatic affections (61d5-64a1), hedonic and algesic affections (64a2 $\pi$ 65b3), gustatory affections (65b4-66d1), olfactory affections (66d1-67a6), auditory affections (67a7-c3) and visual affections (67c4-68d7). What I am calling 'pansomatic' affections Timaeus characterizes as affections common to the whole body ( $\tau \grave{\alpha}$ kovvò $\tau$ These include affections of hot and cold, hard and soft, heavy and light, smooth and rough, in that order. Pansomatic affections, thus, appear to be tactile affections. Indeed, if pansomatic affections are not identical to tactile affections, touch is the most salient form of pansomatic perception. Since Timaeus does not speak of 'touch' or 'tactile' affections, I will continue to speak of 'pansomatic' affections. ${ }^{6}$

In contrast to pansomatic affections, Timaeus characterizes gustatory, olfactory, auditory and

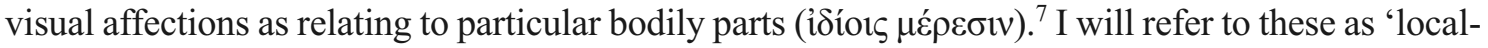
ized' affections. For example, both the tongue and feet can apprehend heat and cold, roughness and smoothness, but only the tongue can apprehend sweetness and bitterness. The former are pansomatic, the latter localized affections.

Hedonic and algesic affections straddle pansomatic and localized affections, for as Timaeus says at the beginning of his account - perhaps precisely to bridge the two kinds - hedonic and algesic affections concur with pansomatic and localized affections:

(A) The most important thing that remains to be said about (1) the affections common to the whole body is the cause of the pleasant and painful [affections] within $(\dot{\varepsilon} v)$ those affections we have discussed

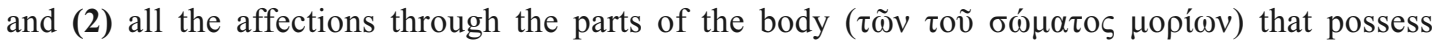

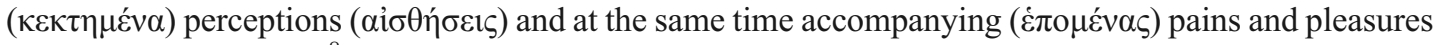
within ( $\dot{\varepsilon} v)$ themselves. ${ }^{8}$

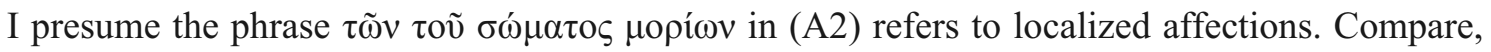
Timaeus' remark as he begins his account of the localized affections:

We have now discussed the common affections of the entire body ... Let us try to speak about the affec-

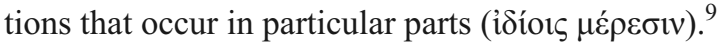

For example, there can be pleasure and pain in gustatory as well as pansomatic perception, for example in touch. Since hedonic and algesic affections concur with, but are distinct from, pansomatic and localized affections, it will be convenient to refer to hedonic and algesic affections generically as 'affective' affections and to contrast these with tactile, gustatory, olfactory, auditory and visual affections as 'non-affective' affections. ${ }^{10}$

I want to draw special attention to the points Timaeus makes in (A1) and (A2) that hedonic and algesic affections occur within ( $\dot{\varepsilon} v)$ pansomatic and localized affections. At the end of this section, following the explanation of the physiology of sense-perceptual pleasure, I will clarify the meaning of this claim.

\footnotetext{
$565 \mathrm{~b} 4$.

${ }^{6}$ Plato speaks of touch ( $\dot{\alpha} \varphi \eta$ ) as a form of $\alpha \grave{\imath} \sigma \theta \eta \sigma ı \varsigma$ at $R .532 \mathrm{e} 6$ and $P h d .75 \mathrm{a} 5$.

8 64a2-6.

9 65b4-6.

${ }^{10} C f$. Cornford (n.1) 267, n.1.

$765 \mathrm{~b} 5$.
} 
Timaeus' explanation of pleasure and pain is divisible into three sections:

64a2-6: introduction;

64a6-c7: discussion of the relation between perception and motion;

64c7-65b3: explanation of pleasure and pain with examples.

The introduction is passage (A). Section two begins with the following programmatic statement:

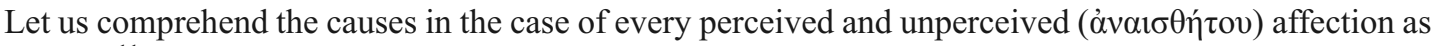
follows. ${ }^{11}$

The explanation of pleasure and pain depends upon an explanation of perceived and unperceived affections. The distinction between perceived and unperceived affections is explained in part by the kinetic properties of the elements that constitute the somatic compounds subject to the affections. Thus, section two discusses the relation between perception and motion. Within this section, Timaeus refers to an earlier discussion, at 55d6-56b6, where he attributes dyskinetic and eukinetic properties to earth, water, air and fire. Fire, air, water and earth are most-to-least kinetic. The kinetic properties of these elements are conceived as a function of their geometric structures. For instance, uniformity and having multiple bases are conducive to rest. Thus, non-uniformity and having few bases are conducive to motion. Timaeus also says that ratios are responsible for motion and rest. Other principles introduced elsewhere in the dialogue bear on the kinetic properties of the elements, for example the principle of attraction of like-to-like and the basic circular motion of the cosmos. ${ }^{12}$

Dyskinetic somatic compounds have a preponderance of dyskinetic elements, earth and water. For example, Timaeus says that compounds such as bone and hair are dyskinetic because they 'are mainly earthy' ${ }^{13}$ In contrast, the most kinetic compounds have a preponderance of fire and air. This is characteristic of the organs of sight and hearing. ${ }^{14}$

Eukinetic elements and compounds facilitate the transmission of affections to the psyche, thus yielding perception. Timaeus explains:

Whenever even a small affection strikes what is naturally eukinetic, it transmits [that affection] through rotary motion, ${ }^{15}$ parts acting upon parts in the same way until, arriving at the $\varphi \rho o ́ v \mu o v$, it reports the power of agent. ${ }^{16}$

Minimally, the $\varphi \rho$ óvinov is identifiable with the psyche. But the psychological theory of Timaeus shares with Republic the view that the psyche is tripartite. So, possibly the $\varphi \rho$ óvirov is identifiable with a specific psychic part. Generally, it is questionable whether specific psychic parts receive specific somatic affections. I return to these questions in section III.

Presently, since upon reaching the psyche, as Timaeus puts it, the somatic affection announces the power of the affecting agent, it may be questioned whether aio $\sigma \eta \eta \sigma \varsigma$ is here conceived as a psychic condition or a somatic-cum-psychic condition. It is quite clear from Timaeus as well as from other late Platonic dialogues that $\alpha$ it $\sigma \theta \eta \sigma ı \varsigma$ is here understood as a somatic-cum-psychic condition. ${ }^{17}$ For example, at 43c4-7 Timaeus describes al̋ $\theta \eta \sigma ı \varsigma$ as follows: 'motions carried

$1164 a 6-7$.

12 It is questionable whether Timaeus has a unified theory of the kinematics of the elements. I know of no satisfactory discussion of this topic, including J.B. Skemp, The Theory of Motion in Plato's Later Dialogues (Cambridge 1942).

$1364 \mathrm{c} 4-5$.

$1464 \mathrm{c} 5-7$.

$15 \kappa v ́ \kappa \lambda \omega_{\imath}$ at $64 \mathrm{~b} 6$ is difficult. D. Zeyl (J. Cooper (ed.), Plato Complete Works (Indianapolis 1997) 1266) translates: 'in a chain reaction'. This is inaccurate. At 64b6-c1 Timaeus continues: 'But the opposite sort of [element], being stable and not moving in a circle, is affected, but does not move any neighbouring element]'. Thus, when an element moves, it rotates.

16 64b3-6.

17 Pace Ganson (n.1). 
through the body impact the soul; all these motions have been called ' $\alpha i \sigma \theta \eta \dot{\sigma} \sigma \varepsilon \varsigma^{\prime}$. Compare Philebus 34a3-5: 'When the soul and body are jointly affected and moved by one and the same affection, if you should call this motion $\alpha i ́ \sigma \theta \eta \sigma 1 \varsigma$, you would say nothing odd'. Similarly, in Theaetetus Socrates famously distinguishes perceiving through ( $\delta i \alpha)$ and perceiving with (dative), and he claims that we perceive through the senses, but with the psyche. ${ }^{18}$ The conception of

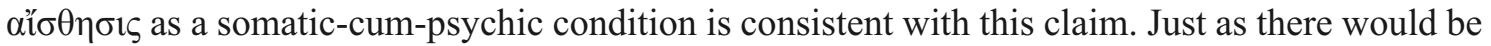

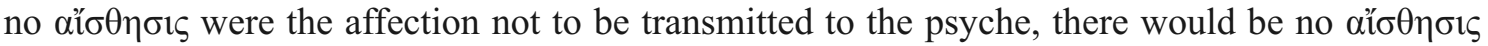
were the psyche to be affected, but without the body directly causing the affection. ${ }^{19}$ Precisely, then, Plato conceives of ai $\sigma \theta \eta \sigma r \varsigma$ as a motion that is transmitted from the body to the psyche.

I turn now to the third section of Timaeus' explanation of pleasure and pain:

(B) (1) We must understand the nature of pleasure and pain as follows. An affection within us that is

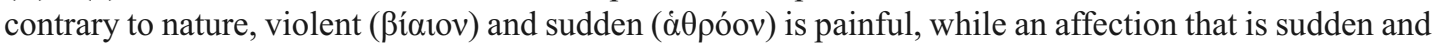

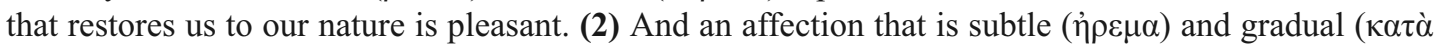

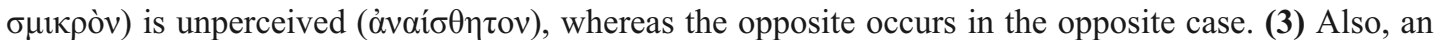

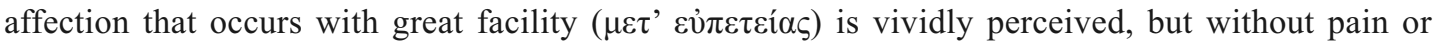
pleasure. ${ }^{20}$

(B1) claims that pleasant and painful affections must be both violent and sudden. Timaeus' conjunction of these properties with their contraries in (B2), subtle and gradual, helps clarify his conception. Moreover, in the remainder of section three (64d5-65b3) Timaeus offers clarifying examples. Precisely, Timaeus gives two sets of examples. The first set (64d5-65a1) relates to subtle and violent affections; the second set $(65 \mathrm{a} 1-\mathrm{b} 3)$ relates to sudden and gradual affections. I discuss the examples in order.

(C) (1) For example, take the affections related to sight, which we previously said was a body that comes into being at day as a natural extension of ourselves. In this case, the cuttings and burnings and all other affections it undergoes do not create within [themselves] pains, nor pleasures when it [specifically, the visual fire projected from the pupil] returns to its same form [that is, returns to its unaffected condition]. Yet visual perceptions are most vivid and clear with respect to whatever affects [the visual fire] and whatever it encounters and contacts. But there is no violence whatsoever when [the visual fire] is severed and reconstituted. (2) Rather, bodies composed of larger parts yield to an agent with difficulty, and they transmit their motions to the whole body, and they possess pleasures and pains - pains when they are alienated [from their natural condition] and pleasures when they are restored to it. ${ }^{21}$

According to the physiology of vision, which Timaeus partially describes earlier in the dialogue (45b2-d3), there exists within the visual organ a pure substance akin to fire but not inflammatory. I have referred to it as 'visual fire'. In the act of seeing, this fire projects from the pupil. More precisely, in daylight the projected visual fire blends with the ambient light, thereby facilitating the fire's receptivity to objects in its environment and enabling it to transmit the chromatic properties of the objects it encounters back through the eye to the psyche. ${ }^{22}$ The cutting, burning and other affections mentioned in (C1), to which the visual fire is subject, consist of the various ways the visual fire can be affected by encountering ambient light, darkness and objects. For example, at $45 \mathrm{~d} 3-4$ Timaeus says that at night the visual fire is severed ( $\dot{\alpha} \tau 0 \tau \dot{\varepsilon} \tau \mu \eta \tau \alpha 1)$, thus severed by

18 Tht. $184 \mathrm{c} 1-85 \mathrm{e} 8$.

${ }^{19} \mathrm{Cf}$. M. Burnyeat, 'Plato on the grammar of perceiving', $C Q 26$ (1976) 29-51, at 51; M. Lee, "Thinking and perception in Plato's Theaetetus', Apeiron 32 (1999) 37-54, at 52. Cf. R. 423a, 524a; Phd. 79c; Phdr. 249b.
${ }^{20} 64 \mathrm{c} 7-\mathrm{d} 5$.

$2164 \mathrm{~d} 5-65 \mathrm{a} 1$.

22 The text does not explain how and why the visual fire's commingling with the ambient light makes the former sensitive to chromatic properties. For Timaeus' explanation of colour, $c f$. Ierodiakonou (n.1). 
darkness; and, in his explanation of colours at 67d1-e6, Timaeus claims that particles released from objects may dilate or constrict the visual fire, dilation producing perception of whiteness, constriction blackness.

The relevance of the example of seeing and visual fire to the explanation of pleasure and pain is that seeing is a vivid and clear form of perception, but not per se pleasant or painful. For example - my example - opening one's eye in daylight is not per se pleasant, nor is the interruption of seeing by the fall of darkness per se painful. The reason Timaeus gives for this is that the visual fire is elementally too subtle a substance; the affections it undergoes do not affect other elements and so other bodily parts. In contrast, as the example in (C2) explains, when somatic compounds whose elemental constituents are relatively bulky are affected, these affections affect other elements and the body more broadly. In other words, such affections have broader physical impact. Pleasure and pain thus require violent, as opposed to subtle, affections.

Timaeus' second set of examples clarifies his conceptions of gradual and sudden affections:

\begin{abstract}
Among those affections ${ }^{23}$ that involve gradual departures and depletions from themselves [that is, from the natural conditions of the bodily compounds they affect], but sudden and rapid replenishments, the affections of depletion are unperceived, whereas the affections of replenishment are perceptual ( $\alpha i \sigma \theta \eta \tau \leftarrow \kappa \alpha)$ and they do not render pains in the mortal part of the psyche, but the greatest pleasures. This is clear in the case of fragrances. But among those affections that are sudden and alienate [the bodily compounds they affect], while they are restored to themselves [that is, to their unaffected conditions] gradually and subtly, all these yield conditions opposite to those just described. Clear examples are cuts and burns of the body. ${ }^{24}$
\end{abstract}

Timaeus understands the pleasures of fragrances to involve sudden and impactful restoration of the olfactory organ to its natural condition, whereas a preceding disintegrative state of the olfactory organ is gradual, subtle, and so not perceived as a painful. ${ }^{25}$ In contrast, cuts and burns of the body involve rapid and violent destructions. Thus, they are painful, whereas the processes through which the cuts and burns are healed are gradual and subtle; thus, they are affectively neutral.

As we have seen, (B1) speaks of pleasure and pain as involving restoration to or disintegration from 'nature', that is, to or from the natural state. By 'natural state' I understand a state of bodily integrity, which is equivalent to health, at least the health of the bodily compound or part. Such restoration and disintegration are specifically associated with affective (hedonic or algesic) affections. Compare Socrates' description in Philebus: 'when in us living beings harmony is dissolved, a disruption of nature and a generation of pains then occur ... But if harmony is again composed ... then pleasure occurs' ${ }^{26}$ Here, harmony is equivalent to bodily integrity and health.

Let us now try to clarify, both logically and physiologically, the relation between restoration and disintegration and hedonic and algesic perceptual affections. First, it seems logically possible to distinguish the concept of a somatic restoration from the concept of a somatic affection that is derived from a restoration. Since an affection is simply a condition of being affected in some way, the somatic process of restoration can be called an 'affection'. But we have been speaking of somatic motion that is transmitted to the soul as an 'affection'. Let us, then, distinguish these as 'restorative' and 'transmissive' affections or processes respectively. The question is whether the somatic affections constitutive of hedonic and algesic affections are themselves constituted by two successive processes: restorative affections and transmissive affections.

${ }^{23}$ Given the predicate expressions $\kappa \varepsilon v \omega ́ \sigma \varepsilon \omega \varsigma$

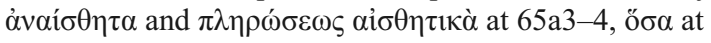
$65 \mathrm{a} 1$ must refer to $\pi \alpha \theta \dot{\eta} \mu \alpha \tau \alpha$ not $\sigma \omega \dot{\mu} \mu \alpha \tau$. However, $\dot{\varepsilon} \alpha \nu \tau \tilde{\omega} \nu$ at $65 \mathrm{a} 3$ cannot refer back to the affections, but to the natural conditions of the bodily parts affected.

$$
\begin{array}{ll}
{ }^{24} & \text { 65a1-b3. } \\
{ }^{25} \text { Cf. R. 584b. } \\
{ }_{2} \text { Phlb. 31d. }
\end{array}
$$


In pursuing this question, we must consider the physiology of hedonic affections more closely. With respect to the body, perception qua somatic-cum-psychic motion begins with the familiar sense-perceptual organs, for example, the tongue, the eye with its visual fire and the flesh. ${ }^{27}$ From these organs, the blood vessels serve as the primary vehicle by which affections are transmitted to the psyche. ${ }^{28}$ For example, in his explanation of taste and gustatory qualities, Timaeus says that particles from food and liquid enter the veins in the tongue that extend to the heart. ${ }^{29}$ The elemental constituents of the food and liquid variously affect these glottal veins, for example drying and constricting them if the food or liquid is earthy. This is experienced as an astringent or harsh flavour. Normally, astringency is unpleasant. That is, normally, the effects of the food or drink on the glottal veins are destructive. ${ }^{30}$ Our question here is whether this destruction occurs throughout the glottal veins that extend to the heart or whether it occurs in a portion of the glottal veins and this destructive affection is transmitted to the heart. If the former, then the restorative and transmissive processes, although logically distinguishable, are coextensive; if the latter, then the processes are sequential. The text is unclear.

The explanation of smell and scents is more informative. Timaeus speaks of veins as conduits for particles that enter through the nostrils. ${ }^{31} \mathrm{He}$ does not specify a terminal point for these olfactory veins. Rather, he says that unpleasant odours roughen and disturb the entire cavity from the top of the head to the navel. ${ }^{32}$ This encourages the view that the restorative and transmissive processes are coextensive. In the absence of counter-evidence, I assume that the olfactory conditions are representative of other perceptual conditions.

In discussing passage (A) above, I emphasized that hedonic and algesic affections are said to occur 'within' pansomatic and localized affections. All perception involves motion transmitted by the body to the psyche. Thus, all perception involves somatic motion. But the relevant somatic motions may have properties of various dimensions. For example, spatio-temporally, the motions may be rapid or gradual. With respect to scope or extent of impact on the body, they may be great or small, hence violent or subtle. With respect to their effect on the organization of the elements constitutive of the somatic compounds but within the parameters of natural conditions, they may variously alter these elements, both spatially and temporally. For example, in the case of one sort of pansomatic affection, warmth derives from separation of elements, coolness from condensation of elements; in the case of one sort of auditory affection, low pitch derives from slow motion of elements, high pitch from quick motion. Finally, with respect to their effect on the natural condition of the body, they may be restorative, disintegrative or neutral.

Since a given affection will simultaneously have properties of some of these various dimensions, the affection may have both affective and non-affective properties. ${ }^{33}$ Indeed, Timaeus maintains that any perceptual affection that has affective properties will have non-affective properties - although, as we have seen, the reverse is not true. In other words, some non-affective perception accompanies all sense-perceptual pleasure and pain. This is because all non-affective affections

${ }^{27}$ I use the word 'flesh' rather than 'skin' because tactile perception can occur by means of the skin at the surface of the body as well as by means of the tissue within the body. Timaeus distinguishes skin $(\delta \varepsilon \dot{\rho} \rho \alpha)$ as a form of flesh $(\sigma \alpha ́ \rho \xi)$ at $75 \mathrm{e} 8-76 \mathrm{a} 2$.

${ }^{28}$ I agree with Brisson (n.1 1997) 157-59. Cf. 67b24, 70a7-c1, 77d6-e6. Contrast Karfík (n.1) n.45, who thinks perceptual affections are transmitted to the immortal psyche and that fire is the medium of transmission. (It is also important to recall that Plato and his contemporaries did not distinguish nerves from blood vessels.)

${ }^{29} 65 \mathrm{c} 7-\mathrm{d} 1$. These veins are described as 'testers'
( subject about the qualities of the food or drink before swallowing.

${ }^{30}$ I say 'normally' because if the veins are abnormally distended then astringent food in the appropriate quantity should restore them to their natural condition and thus be pleasant.

$31 \varphi \lambda \dot{\beta} \beta \varepsilon \varsigma$ at $66 \mathrm{~d} 4$.

32 67a4-5.

${ }^{33}$ Recall that while I translate $\pi \alpha \dot{\theta} \eta \mu \alpha$ as 'affection', I use 'affective' to refer to the genus of which pleasure and pain are species. 
must either occur within the parameters of the natural state and thus be affectively neutral or involve restorations to or disintegrations from the natural state and thus be pleasant or painful.

\section{The psychology of sense-perceptual pleasure}

Qua $\alpha i ̋ \theta \eta \sigma 1 \varsigma$, sense-perceptual pleasure requires that the restorative affection of the body affect

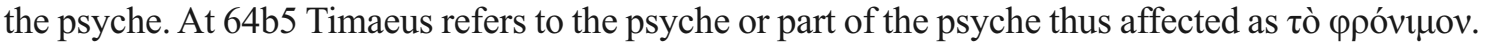
Elsewhere in Plato's corpus tò $\varphi \rho o ́ v i \mu o v$ refers to the rational part of the psyche. ${ }^{34}$ But at $65 \mathrm{a} 5$, in the context of describing sense-perceptual pleasures not preceded by pain, of which olfactory pleasures are an example, Timaeus speaks of the mortal part $\left(\tau \tilde{\omega}_{\imath} \theta v \eta \tau \tilde{\omega}\right)$ of the psyche as the part affected. By 'mortal part' Timaeus may intend the mortal part as a whole or one of its two subparts, the emotional or appetitive part. Regardless, the mortal part of the psyche is not the rational part, which is immortal. Likewise, recall that at $61 \mathrm{c} 7-\mathrm{d} 2$, as he prepares to discuss perceptual affections, Timaeus says: 'Yet we have not discussed how flesh and related bodily parts are generated, nor the mortal part ( $\theta v \eta \tau o ́ v)$ of the psyche. But we cannot adequately discuss the perceptual affections without these'. Thus, there is an apparent contradiction in the specification of the psychic part affected in sense-perceptual pleasure.

The contradiction cannot be resolved on the grounds that, when tò $\varphi \rho o ́ v \mu o v$ is used, Timaeus refers to one kind of sense-perceptual pleasure, whereas when the mortal part is mentioned he

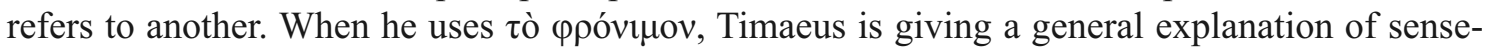
perceptual pleasure.

I propose the following solution. ${ }^{35}$ Timaeus uses $\tau$ ò $\varphi \rho o ́ v i \mu o v$ at $64 \mathrm{~b} 5$ to refer to the rational part of the psyche, but this reference is consistent with Timaeus' references to the mortal part of the psyche at $61 \mathrm{c} 7-8$ and $65 \mathrm{a} 5$ because both psychic parts may be involved in sense-perceptual pleasure and in sense-perception generally. Since sense-perceptual judgments occur, we might expect that sense-perception can involve various psychic parts. In fact, there is textual evidence that sense-perceptual pleasure can variously involve all three psychic parts.

At 77a3-c5 Timaeus discusses plant life. He claims that plants possess only the appetitive form of psyche. As such, plants are incapable of 'belief, reasoning or understanding' ${ }^{36}$ However, the appetitive psyche endows plants with the capacity for 'pleasant and painful perception with desires' ${ }^{37}$ I assume that botanical desires include thirst and hunger and that pleasant perception includes nutrition and hydration.

In speaking of a plant's nutritional and hydrational affective perceptions, Timaeus is, I presume, using $\alpha$ ľ $\sigma \eta \eta \sigma \curlywedge \varsigma$ to refer to bodily perception, not perception by means of one of the five classical sense organs specifically. The alternative is that dehydrated or malnourished plants enjoy the taste of water or nutrients in the soil. This seems implausible. Admittedly, we are already in the bizarre realm of plant perception. But from within this realm, one may argue that insofar as the tongue is the organ of taste and plants lack a homologous organ, plants' affective perceptions should not be conceived as gustatory. Plant perception, thus, provides some evidence that the appetitive psyche is responsible for some affective perception, albeit not sense-perceptual pleasure or pain.

As discussed above, in his account of taste Timaeus refers to glottal veins leading to the heart. The heart is the principal organ associated with the emotional part of the mortal psyche. If the heart is the terminal point in the transmission of gustatory affections, then the emotional part of the psyche apprehends tastes and thus pleasant and unpleasant tastes. But if the emotional psyche does not apprehend tastes, the heart must transmit the gustatory affections elsewhere. Evidence that the heart or emotional psyche is not the terminal point of gustatory affections derives from

${ }^{34}$ R. 530c1, 586d7.

${ }^{35}$ For a different proposal, $c f$. O’Brien (n.1 1997) 298-303.
$3677 \mathrm{~b} 5$.

37 77b5-6. 
the following considerations. First, in Timaeus, as in Republic, the emotional psyche is, as my translation of $\theta v$ uo $\zeta$ indicates, associated with emotion, saliently, anger. ${ }^{38}$ Of course, the emotional part may have multiple functions. However, aside from the passage in Timaeus that describes the glottal veins as descending to the heart, there is no positive evidence that the heart or emotional psyche is responsible for any specific form of sense perception. A further consideration relates to Timaeus' discussion of the liver at 71a3-e6. The liver is identified as the principal organ associated with the appetitive psyche. This psychic part is said to be incapable of reason, yet sensitive to certain sense-perceptual qualities, including the gustatory qualities of sweetness and bitterness. ${ }^{39}$

In explaining auditory qualities at $67 \mathrm{a} 7-\mathrm{c} 3$, Timaeus characterizes sound as a stroke upon the brain and blood by air channeled through the ear. He says that this auditory affection is transmitted from the brain, evidently by means of the blood vessels, to the liver. Thus, hearing does not occur until the somatic affection reaches the liver and the appetitive psyche. ${ }^{40}$

Given that the appetitive psyche is responsible for tactile, gustatory and auditory perception, it seems reasonable to infer that the appetitive psyche is responsible for the perception of all of what may be called 'basic' sense-perceptual qualities, that is, colours, sounds, tastes, scents, tactile qualities, as well as sense-perceptual pleasures and pains. ${ }^{41}$

Regarding this last point, consider a claim Timaeus makes in the context of discussing sounds at 80a2-b8. Certain hedonic sounds, he says, 'give pleasure (i்ovท') to the unintelligent and delight

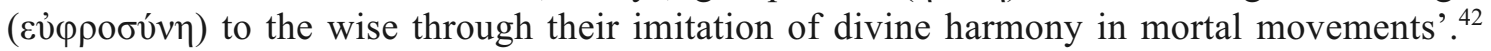
Timaeus here refers to two hedonic psychic states and uses distinct terms for each. Plato only uses

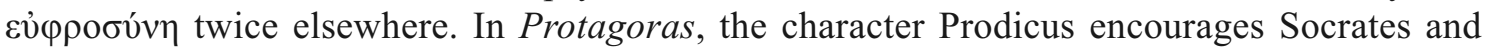
Protagoras to indulge the audience by resuming their suspended discussion:

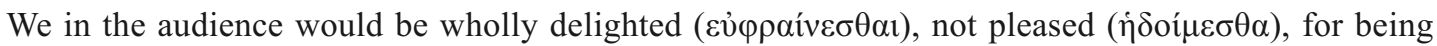

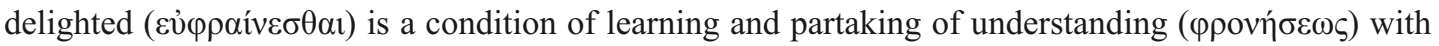

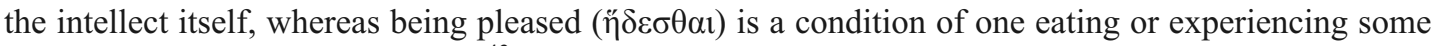
other pleasure with the body itself. ${ }^{43}$

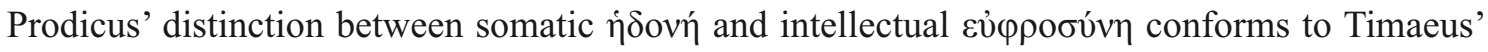
distinction.

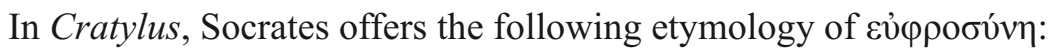

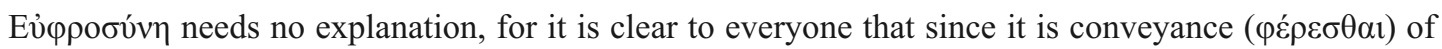

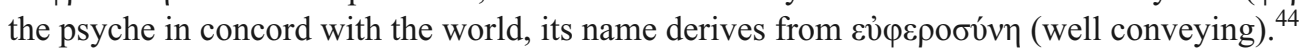

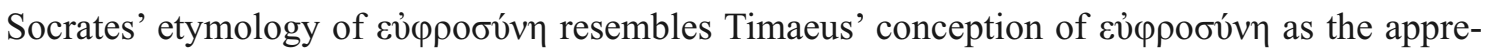
hension of divine harmony in mortal motion.

Hence, it appears that the immortal psyche can apprehend or, rather, interpret sense-perceptual affections. Evidently, the immortal psyche interprets sense-perceptual affections differently from the way the mortal psyche apprehends them, although it is unclear what the difference amounts to. Presumably, in the case of auditory pleasure, the immortal psyche apprehends rational structures in the hedonic auditory affection, whereas the mortal psyche, precisely the appetitive psyche, does not.

38 70a2-7.

$3971 \mathrm{c} 6$.

${ }^{40}$ Cf. Barker (n.1).

${ }^{41}$ This conclusion is supported by the further negative consideration that the rational psyche, located in the brain, is not responsible for perception, where 'percep- tion' is here understood as the apprehension of basic sense-perceptual qualities. $C f$. Barker (n.1) 87.

42 80b5-8.

43 Prt. 337c1-4.

${ }^{44}$ Cra. 419d4-9. 
In conclusion, various psychic parts can play various roles in sense-perceptual pleasure. The appetitive psyche apprehends hedonic perceptual affections. But all psychic parts can transmit perceptual affections. In auditory perception, the rational psyche transmits affections. Presumably, it does so in the case of all forms of perception where the sense-perceptual organs are located about the head. Further support for this suggestion derives from Timaeus' description of twin veins that cross and descend from the head through the trunk:

[The lesser gods] split up these veins in the region of the head and wove the ends so as to pass across one another in opposite directions, slanting those from the right towards the left side of the body and those from the left towards the right side ... so that the affection of perceptions ( $\tau$ ò $\tau \tilde{\omega} v \alpha i \sigma \theta \eta \dot{\sigma} \sigma \omega v$

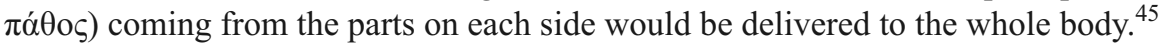

We have seen that, in taste, there is reason to believe that the heart transmits affections to the liver. In hearing, the liver can transmit affections back to the brain. Here, the immortal psyche plays the additional role of rational interpreter of the hedonic perceptual affection. Thus - to return to the problem posed at the beginning of this section - Timaeus could, and I suggest does, use $\tau$ ò

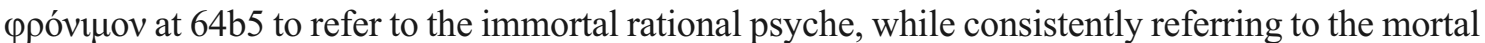
psyche at $61 \mathrm{c} 7-8$ and $65 \mathrm{a} 5$. Thus, when at 64b5-6 Timaeus says that the somatic affection 'arrives at the $\varphi \rho v_{v} \mu \nu^{\prime}$ ' and 'reports the power of agent', he must be referring to an act of sense-perceptual judgment by the rational psyche.

So much for which psychic parts sense-perceptual pleasure involves and the nature of their involvement. I want to consider one further point regarding the psychology of sense-perceptual pleasure. What sort of motion of the appetitive psyche does sense-perceptual pleasure involve? Is it isomorphic to the motion of the somatic affection? Is it restorative? In considering this question, it is convenient to draw a distinction between describing the psychic affection in spatial terms, that is, in terms used to describe the somatic affection, and describing the psychic affection in intentional or in phenomenal psychological terms, for example as a paívo $\mu \varepsilon v o v$, phenomenal quality, or act of awareness or comprehension. While Plato is willing to talk in terms of $\varphi \alpha i v o \mu \varepsilon v \alpha$ and phenomenal qualities, it is a striking feature of Timaeus' airía of pleasure that phenomenal and intentional description plays little role. Granted the absence or dearth of intentional and phenomenal psychological language, I will focus on the psychic motion of sense-perceptual pleasure in terms equivalent or analogous to those of somatic affections.

Interpretive difficulties here are severe. The basic problem is that Timaeus never says what the mortal psyche is. On the one hand, the mortal psyche qua psyche must be distinguished from the body; on the other hand, the mortal psyche must be distinguished from the immortal psyche. ${ }^{46}$ Let's begin with Timaeus' description of marrow ( $\mu v \varepsilon \lambda$ ó $\varsigma$ ), since marrow is the physiological stuff that fundamentally binds the psyche, in each of its three forms, to the body.

At 73b2-e1 Timaeus describes the formation of marrow as the starting point ( $\dot{\alpha} \rho \chi \eta \dot{)}$ of the body. Timaeus uses $\dot{\alpha} \rho \chi \eta$ because he conceptualizes the construction of the body from the inside outward. Marrow is, thus, the most interior stuff of the body. Marrow is encased in or surrounded by bone, bone by sinew, sinew by flesh and flesh by skin.

Timaeus characterizes the marrow and its function in agricultural terms. He refers to the marrow as a seed-mixture ( $\pi \alpha v \sigma \pi \varepsilon \rho \mu i ́ \alpha)$ - this insofar as marrow is composed of the triangles that constitute each of the four somatic elements in their purest forms. ${ }^{47}$ As such, marrow is a sort of pansomatic substance. Timaeus subsequently refers to the marrow as plough-land (ópovp $\alpha$ ). ${ }^{48}$ Marrow thus serves as the soil in which the psyche is rooted. Indeed, Timaeus speaks of the psyche's bond to

$4577 \mathrm{~d} 6-\mathrm{e} 6$.

${ }^{46}$ Contributions to the problem are scarce. Karfík (n.1) is a notable exception. $C f$. also Pradeau (n.1).
47 73c1; cf. 86c3, $91 \mathrm{~b} 1$.

$4873 \mathrm{c} 7$. 


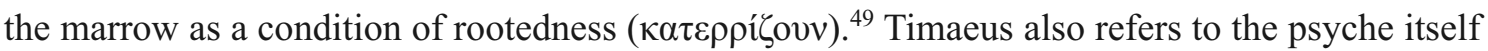
as seed $(\sigma \pi \varepsilon \dot{\varepsilon} \mu \alpha){ }^{50}$ Accordingly, the psyche is conceived like a plant that is attached to and grows from the soil of the marrow. So long as the psyche remains bound to the marrow, the creature lives. Death occurs when the myeloid bonds can no longer hold the psyche. ${ }^{51}$

Timaeus' most explicit description of the relation between marrow and psyche occurs at $73 \mathrm{c} 5$ d7:

[The lesser gods] divided the marrow into shapes corresponding in sort and size to those that the several kinds [of psyche] were originally allotted. And [they] molded one part into a spherical shape like a plough-land that was to have the divine seed within itself. This part of the marrow they named 'brain' ( $\dot{\xi} \gamma \kappa \varepsilon ́ \varphi \alpha \lambda \circ v)$, signifying that when each living creature was completed, the vessel containing this should

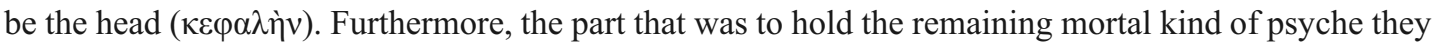
divided into shapes both round and elongated, naming them all 'marrow'. And from these [myeloid forms], as if from anchors, casting the bonds of the entire psyche, they produced our entire body all around this.

The shapes of the psychic parts conform to the shapes of the marrow in which they are rooted. Thus, the immortal rational part of the psyche is spherical like the brain. ${ }^{52}$ The mortal parts of the psyche are more or less cylindrical, that is, simultaneously 'round and elongated'. Accordingly, one might think that the mortal psyche resides in the vertebrae, rib cage, bones of the upper and lower arms and legs, and - although it is an exception to the loosely cylindrical shape of the other myeloid parts - pelvis. In short, one might think that the mortal psyche resides in the skeleton sans skull and jawbone. But this hypothesis is untenable in view of Timaeus' account at 74e1$75 \mathrm{c} 7$ of the relation between bone, flesh density and cognitive capacities. Timaeus claims that certain bones are impercipient or unintelligent for one of two reasons. Either they are covered in too much flesh or their marrow lacks adequate psyche. These bones include the thighs, shins and 'parts about the hips', the bones of the upper arms and forearms, 'all other parts where there are no joints' and, finally, an unspecified set of bones 'that are devoid of intelligence due to the paucity of psyche in the marrow'. ${ }^{53}$ This suggests that the primary site of the mortal psyche is the vertebrae. ${ }^{54}$ Moreover, since elsewhere Timaeus states that the diaphragm separates the emotional psyche from the appetitive psyche, ${ }^{55}$ we can affirm that the emotional psyche is rooted in the upper vertebrae, while the appetitive psyche is rooted in the lower vertebrae.

I now want to focus on the final line of the passage: 'And from these [myeloid forms], as if from anchors, casting the bonds of the entire psyche, [the lesser gods] produced our entire body all around this'. Here the myeloid parts are conceived as anchoring the psyche, and the various parts of the psyche are bound to the myeloid parts. ${ }^{56}$ Moreover, the bonds or chains of the psyche are conceived as cast outward from the myeloid bed in which they are rooted. This may suggest that the psyche consists of strands, but perhaps one should not take the metaphor too literally. In any case, one question this raises is how far beyond the myeloid bed the psyche extends. The psyche surely does not extend into the bones themselves since this would endow the bones with psychological capacities. The psyche could, however, extend into blood vessels (including nerves, albeit conceived as blood vessels) leading from the spine and thus throughout the body. I will offer

\footnotetext{
$4973 \mathrm{c} 4$.

$5073 \mathrm{c} 7$.

51 On the loosening of the myeloid bonds in aging and the release of the psyche in death, see 81c6-e5.

52 The rootedness of the immortal psyche in the brain makes it difficult to understand how the motion of the immortal psyche can be circular.
}

\footnotetext{
$5374 \mathrm{e} 10-75 \mathrm{a} 4$.

${ }^{54}$ It is unclear whether the bones of the hands and feet are to be included. I presume Timaeus views the hands as tactile perceptual instruments, inter alia.

${ }^{55}$ 69d6-72e2, esp. 69e5-70a2.

${ }^{56}$ For the phrase $\psi v \chi \tilde{\eta} \varsigma \delta \varepsilon \sigma \mu$ ó $\varsigma$, see $73 \mathrm{~b} 3,73 \mathrm{~d} 6$, $81 \mathrm{~d} 6,81 \mathrm{~d} 7$.
} 
reasons for thinking so and, moreover, that by means of such vessels the psyche extends to certain bodily organs.

At 91a1-d5 Timaeus describes the lesser gods' construction of sexual lust in males and females.

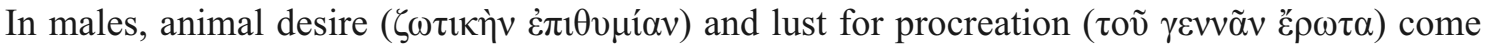
into being in what may be called the 'penile vein', ${ }^{57}$ through the influence of the seminal marrow that originates in the head and runs down the spine. A consequence is that the genitals are disobedient ( $\dot{\alpha} \pi \varepsilon 1 \theta \dot{\varepsilon} \varsigma)$ and self-governing ( $\alpha \dot{v} \tau о \kappa \rho \alpha \tau \dot{\varepsilon} \varsigma)$, ' like an animal heedless of reason and driven by desire [that] strives to overpower everything, ${ }^{58}$ Similarly in females, the womb is characterized as an 'animal desirous of child-bearing' and also 'subject to distemper' when it remains 'without fruit' much beyond its appropriate season. ${ }^{59}$ In both cases, then, bodily organs or parts that lie outside of the skull and vertebrae are characterized as having, or being subject to, psychological conditions. While the penis or penile vein is connected to the brain and spinal marrow, there is reason to believe that the womb is not. Plato, like Aristotle, denies that women contribute seed, which originates in the brain, to reproduction. ${ }^{60}$ Accordingly, sexual or procreative desire in women in particular provides good evidence that although the psyche is rooted in the marrow, it extends beyond the marrow, through blood vessels, to certain bodily organs or parts.

This conclusion corroborates the supposition that the mortal psyche also extends to the heart and liver, among other organs, which, as we have seen, are saliently associated with the capacities and functions of the emotional and appetitive psyches. ${ }^{61}$ Note also that the psyche's extension into the body beyond the marrow is compatible with Timaeus' conception of perception as entailing that physiological affections penetrate to the psyche. That is, the psyche may extend beyond the marrow, but still remain relatively restricted in its extension within the body. In most cases, the psyche is restricted to organs relatively deep within the body.

The notion that Timaeus conceives of psyche as spatial but non-somatic is strange, but uncontroversial. ${ }^{62}$ Precisely what sort of stuff the mortal psyche in particular consists of remains unclear. Indeed, here our treatment becomes quite speculative. As we said, the mortal psyche qua psyche cannot be somatic. Yet it must differ from the immortal psyche both in its capacities and, especially, its mortality. I suggest that the mortal psyche is composed of the same stuff as the immortal psyche, but of less pure quality. At 41d4-7 Timaeus describes the demiurge's creation of human psyches using the mixture of Sameness, Difference and Being that he used to create the cosmic psyche. However, Timaeus specifies that the mixture now used is twice or thrice less pure than the original mixture. I presume such relative impurity is to be construed in one or both of two ways: one, in terms of relatively less well-proportioned quantities of the indivisible and divisible species of Sameness, Difference and Being, ${ }^{63}$ two, in terms of relatively less well-proportioned harmonic intervals of the parts of the mixture of the former. ${ }^{64}$ With respect to psychological capacities, I presume relative impurities yield relative psychological weaknesses. For example, the rational capacities of the human psyche are weaker than those of the cosmic psyche. Likewise, I suggest, the psychological capacities of the mortal psyche are weaker than those of the rational psyche; and those of the appetitive psyche weaker than those of the emotional psyche. ${ }^{65}$ Finally, I suggest that due to the relatively less well-proportioned quantities of its ingredients and the relatively less

\footnotetext{
${ }^{57}$ It is unclear whether this is the urethra, vas deferens, or some larger vascular extension.

58 91b6-7.

59 91c1-4.

${ }^{60} C f$. Aristot. GA 727a26-30.

${ }^{61} C f .70 \mathrm{a} 2-\mathrm{d} 6$ and $70 \mathrm{~d} 7-71 \mathrm{e} 2$ for further discussion of the location, or rather extension, of the emotional and appetitive parts of the psyche about the chest and abdomen respectively, the organs saliently associated
}

with them and correlative psychological conditions.

${ }^{62}$ Cf. 36b6-e5. Cf. also Johansen (n.1 2004) 13842; Karfík (n.1). I disagree with Karfík, and Lautner (n.1) who follows him, that the mortal psyche is simply the motion of certain bodily organs, tissues or parts.

${ }^{63}$ Cf. 35a1-8.

${ }^{64}$ Cf. 35b1-36b6.

${ }^{65}$ This needn't imply that the capacities of higher types of psyche include those of lower types. 
well-proportioned harmonic intervals according to which the parts of the mixtures of these ingredients are structured, the mortal psyche is relatively unstable, ultimately destructible and hence mortal.

Finally, let's turn to the question whether in sense-perceptual pleasure the motion of the appetitive psyche is restorative. One reason to think so is by analogy with the condition of the immortal psyche. Timaeus explicitly says that the circuits of the immortal psyche, when implanted in a body, become disorderly. The cultivation of rationality, therefore, involves restoring the natural motion of the immortal psyche. Moreover, Timaeus explicitly says that the non-circular motions of perception particularly contribute to the disorder of the immortal psyche:

These circuits [of the immortal psyche], being confined in a strong river, neither controlled it nor were controlled, but caused and suffered violent motions so that the whole creature moved, but advanced at hazard without order or method, having all six motions; for they went forward and backward, right and left, up and down, straying every way in all six directions. For strong as was the tide that brought them nourishment, flooding them and ebbing away, a yet greater tumult was caused by the affections of the things that assailed them, when some creature's body chanced to encounter alien fire from outside or solid concretion of earth and softly gliding waters or was overtaken by the blast of air-borne winds. And the motions caused by all these things passed through the body to the psyche and assailed it. ${ }^{66}$

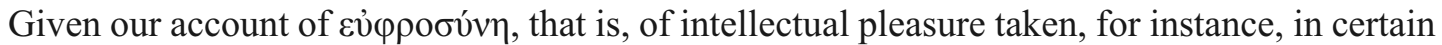
sounds, one can explain the irrationalizing effects of perceptual affections specifically on the grounds that much of what we perceive in the sublunary sphere is sub-beautiful, which entails, by Plato's lights, that its form or structure or organization is relatively disproportional. ${ }^{67}$

By analogy with the immortal psyche, then, there is reason to think that the mortal psyche may also be subject to structural or formal restoration and so also deformation and destruction. For instance, one's perceptual and appetitive capacities or functions might come to be in better or worse conditions. Timaeus does not actually speak of perceptual capacities or functions as such; however, he addresses other aspects of the appetitive and emotional psyche. For example, as we discussed, failure to conceive at the appropriate time disturbs a woman's temperament. Elsewhere, Timaeus describes how congenital osteoporosis engenders a libidinous psyche ${ }^{68}$ Furthermore, Timaeus describes how various physiological imbalances can harm all 'three loci of the psyche ... producing various kinds of distemper and dysthymia, recklessness and cowardice, as well as forgetfulness and incapacity to learn' ${ }^{69}$ In addition to such somatic causes of psychological disorders, Timaeus also refers to psychological, more precisely psychosocial, causes of psychological disorders as well as the psychosocial remedies for these disorders. ${ }^{70}$

Granting that the mortal psyche is subject to restoration and destruction, it remains difficult to ascertain whether Plato thinks sense-perceptual pleasures themselves involve psychic restorations. The problem becomes obvious when one considers that normal occurrences of sense-perceptual pleasure and pain require, within certain parameters, healthy functioning of the psychosomatic sense-perceptual apparatuses. For example, honey may taste bitter and unpleasant to a sick person and failure to register pain when one is wounded may occur when one's sense-perceptual faculties are malfunctioning. Of course, extremely bright lights or loud sounds can impair or damage the sense-perceptual faculties. But, again, healthy sense-perception seems to require that the senseperceptual faculties be intact. Furthermore, it is unclear whether such problems and their remedies are explicable in somatic terms, psychic terms or both. Unfortunately, Timaeus does not examine such cases.
$6643 \mathrm{a}-\mathrm{c}$.
${ }^{67} \mathrm{Cf}$. "the good is always beautiful and the beautiful
$6886 \mathrm{c} 3-\mathrm{e} 5$.
$6986 \mathrm{e} 5-87 \mathrm{a} 7$. is not without measure' (87c4-5).
$7087 \mathrm{~b} 3-8$. 
In light of such considerations and lacking further evidence, I suggest that while sense-perceptual pleasure involves somatic restoration, it does not involve psychic restoration. Thus, in senseperceptual pleasure the appetitive psyche does not undergo restoration isomorphic to the restoration of the body.

\section{Two kinds of perceptual pleasure?}

At 42a3-b1, Timaeus says that when psyches are implanted in human bodies, there arise:

(D) first, perception ( $\alpha$ آ $\sigma \theta \eta \sigma \iota)$... second, desire (๕̌ $\rho \omega \tau \alpha)$ blended with pleasure and pain, and besides fear and anger ...

We need to explain why in (D) Timaeus distinguishes perception from pleasure and pain and claims that perception actually arises prior to pleasure and pain, whereas at $64 \mathrm{a} 2-65 \mathrm{~b} 3$ he deliberately explains how pleasure and pain occur within non-affective perceptual affections and treats sense-perceptual pleasure as a form of aî $\sigma \eta \eta \sigma i c$.

This problem is compounded by a passage at $69 \mathrm{c} 3-\mathrm{d} 6$ whose content is reminiscent of (D). There, Timaeus describes the effects of the lesser gods' creation of the mortal psyche and its 'necessary affections':

(E) first, pleasure, the strongest lure of evil; next, pains that take flight from good; daring moreover and fear, a pair of unwise counsellors; anger, hard to entreat; and hope too easily led astray. These they combined with irrational perception ( $\alpha i \sigma \theta \dot{\sigma} \sigma \varepsilon l)$ and desire ( $\check{\rho} \rho \omega \tau \imath)$ that shrinks from no venture, and so in the manner necessary they compounded the mortal element.

Here, pleasure and pain are not characterized as arising prior to 'irrational perception', but combined with it. ${ }^{71}$ Still, pleasure and pain are distinguished from perception. Thus, (E) also appears inconsistent with the explanation of pleasure and pain as forms of aľ $\sigma 0 \eta \sigma ı$ at $64 \mathrm{a} 2-65 \mathrm{~b} 3$.

I propose the following solution. Timaeus has wide and narrow uses of alo $\theta \eta \sigma r c$. The wide use includes all somatic-cum-psychic affections. The narrow use is more restrictive in two respects. First, it is restricted to somatic-cum-psychic affections sans affective aspect. Second, it is restricted to somatic-cum-psychic affections that involve qualities of the five classical forms of sense-perception: colours, sounds, smells, flavours and, in the case of pansomatic affections, heat and cold, roughness and smoothness, heaviness and lightness, hardness and softness. I will refer to these pansomatic qualities as 'non-affective pansomatic qualities'. This second restriction implies that there are somatic-cum-psychic affections that need not involve sense-perceptual qualities. I will defend this view shortly. Presently, I suggest that in (D) and (E), Timaeus uses aǐ $\sigma \theta \eta \sigma ı \varsigma$ narrowly;

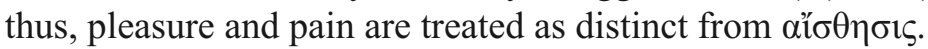

In addition to his wide and narrow uses of $\alpha$ ľ $\sigma \theta \eta \sigma 1 \varsigma$, I suggest that Timaeus implicitly distinguishes two kinds of bodily or perceptual pleasure and pain, that is, two kinds of somatic-cumpsychic affective affection. One kind is what I have been calling sense-perceptual pleasure and pain, that is, pleasure and pain that occur within non-affective sense-perceptual affections, as explained at 64a2-65b3. But I suggest that in (D) and (E) he refers to bodily or perceptual pleasure and pain that can occur independently of the classical sense-perceptual qualities. I will call these pleasures and pains 'brute'. I emphasize that Timaeus does not explicitly draw these distinctions. Nonetheless, I suggest that they are implicit in his discussion and that they explain the appearance of inconsistency between (D) and (E) and the treatment of pleasure at $64 \mathrm{a} 2-65 \mathrm{~b} 3$.

\footnotetext{
71 Johansen (n.1 2000) and (n.1 2004) 145-52 discusses the inconsistency between (D) and (E) in this respect.
} 
Brute pleasures and pains relate to nutrition, hydration and sex. For example, the pleasure of seminal ejaculation is a brute pleasure; hunger and thirst are brute pains. Plato also recognizes brute sexual pain, the ache of lust, as well as the brute pleasures of remedying hunger and thirst. Evidence for Plato's recognition of these brute pleasures and pains derives mainly from texts outside of Timaeus. For example, at Gorgias 494b-c and 496c-e, Republic 585b-d and Philebus 31e-32a Socrates identifies hunger and thirst and eating and drinking as bodily pains and pleasures. At Republic 437d-438a Socrates offers hunger and thirst as the clearest examples of $\dot{\varepsilon} \pi 1 \theta u \mu i ́ \alpha$ and argues that the objects of these desires are food and drink. At Gorgias 494e Socrates refers to and at Philebus 46c-47b alludes to sexual pains and pleasures. At Republic 436a11 Socrates speaks of the desire for the 'pleasures of nourishment and sex'. ${ }^{72}$

Brute pleasures and pains are not pleasures of sight, hearing or smell. Brute pleasures of slaking thirst and satisfying hunger specifically are also not pleasures of taste, nor are the pains of hunger and thirst. ${ }^{73}$ It is unclear whether brute pleasures and pains are pansomatic. As we will see, Timaeus views sexual pleasures and pains as localized. It is unclear whether Timaeus views nutritional and hydrational pleasures and pains as localized. Furthermore, it seems that brute pleasures and pains may occur independently of non-affective pansomatic qualities; that is, it seems that brute pleasures and pains need not involve heat or cold, smoothness or roughness, hardness or softness, heaviness or lightness.

But brute pleasures and pains are forms of $\alpha$ li $\sigma \theta \eta \sigma i \varsigma ;$ they are somatic-cum-psychic processes. In short, there are two forms of perceptual pleasure, those that involve the classical sense-perceptual qualities and those that needn't. Brute pleasures remain relatively inadequately theorized throughout Plato's corpus.

The preceding is a proposal for resolving the inconsistencies that arise from (D) and (E). I have yet to offer much supporting evidence. In Timaeus Timaeus does not explicitly discuss hunger, thirst and the correlative satisfactions. However, he does explain the physiological process of nourishment as one of replenishment: food and drink are decomposed and transformed into blood and 'every member draws ... from [the blood] to replenish the base of its depleted part' ${ }^{74}$ There is, however, more explicit evidence relating to sexual pleasure and pain. At $42 \mathrm{a} 7$ and $69 \mathrm{~d} 5$, that is, in (D) and (E), Timaeus uses "̌ $\rho \omega \varsigma$ to refer to the desires associated with pleasure and pain. I do not think he solely or even principally intends 'sexual desire'; thus, I have not translated '̌́ $\omega \varsigma$ as 'lust'. Rather I think he principally has in mind hunger, thirst and their satisfactions. Still, sexual desire, which he conceives as a pain, and sexual pleasure are among the conditions he intends. Evidence for this comes from Timaeus' reference to sexual desires, that is, pains, and pleasures at $86 \mathrm{c} 3-7$ :

When the seed in a man's marrow has grown copious and overflowing like a tree whose fruit is disproportionately abundant, he continually suffers from great pains and great pleasures in his desires

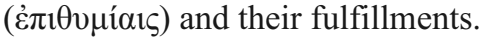

Precisely, I presume Timaeus conceives of sexual desire as a pain and of sexual fulfillment, through the ejaculation of semen, as a pleasure.

Assuming that the preceding evidence supports the implicit distinction between sense-perceptual and brute pleasure and pain, one may still wonder why, if Timaeus intently discusses senseperceptual pleasures and pains at 64a2-65b3, he implicitly refers to a distinct set of pleasures and pains at (D) and (E). I suggest that Plato generally conceives of brute pleasures and pains as the most basic kind of pleasures and pains and, with respect to pleasures, the most pedestrian objects of desire. In passages and texts that focus on hedonic and algesic theorizing, namely Republic 9, Philebus and, I am suggesting, Timaeus 64a2-65b3, Plato is, inter alia, intent upon clarifying other

${ }^{72}$ Cf. Prt. 353c6-7; Hp. Ma. 298e1.

74 81a1-2.

${ }^{73}$ Cf. R. 437d-438a. 
kinds of pleasure and pain or showing that there are other kinds of pleasure and pain in addition to the brute kind. At Timaeus $64 \mathrm{a} 2-65 \mathrm{~b} 3$ specifically, the treatment of pleasure and pain is limited to sense-perceptual pleasure and pain since this passage falls within the larger passage $61 \mathrm{c} 3-68 \mathrm{~d} 7$ where Timaeus' objective is to explain sense-perceptual affections generally. Accordingly, Timaeus' explanation of sense-perceptual pleasure and pain at $64 \mathrm{a} 2-65 \mathrm{~b} 3$ treats a kind of pleasure and pain that, from the perspective of Platonic affective theorizing, is atypical. Timaeus' explanation of sense-perceptual pleasure is, in fact, the earliest surviving sustained and focused account of the subject in Greek thought. ${ }^{75}$

75 The modifiers 'surviving', 'sustained', 'focused' and 'sense-perceptual' are important. We certainly have some evidence of earlier physiological accounts of pleasure and related affective states such as joy. Indeed, it is worth emphasizing that physicalist or materialist conceptions of the psyche were the norm in early Greek philosophy and science. For Empedocles, $c f$. D. Wolfsdorf, 'Empedocles and his ancient readers on pleasure and desire', OSAPh 36 (2009) 1-71; for Anaxagoras, $c f$. J. Warren, 'Anaxagoras on perception, pleasure, and pain', OSAPh 33 (2007) 19-54; for Diogenes of Apollonia and some early medical sources, $c f$. D. Wolfsdorf, 'Pleasure in the early physical tradition', in Pleasure in Ancient Greek Philosophy (Cambridge 2013) 29-39. Strangely - whatever other influence Democritus might have had on Plato's Timaeus (on which $c f$., for example, P.-M. Morel, 'Le Timée, Démocrite et la nécessité', in M. Dixsaut and A. Brancacci (eds), Platon Source des
Présocratiques (Paris 2002) 129-50) - there is no compelling evidence that he presented a physiological explanation of pleasure or $\varepsilon \dot{v} \theta v \mu i$ í. In particular, Theophrastus' On Perceptions says nothing about Democritus on affective states. But $c f$., for example, C.C.W. Taylor, 'Pleasure, knowledge, and sensation in Democritus', Phronesis 12 (1967) 6-27; G. Vlastos, 'Ethics and physics in Democritus', in D.J. Furley and R.E. Allen (eds), Studies in Presocratic Philosophy 2 (London 1975) 381-408. For an intriguing discussion of the role of language and its physiological effects on the emotions in Gorgias, $c f$. P.S. Horky, 'The imprint of the soul: psychosomatic affections in Plato, Gorgias, and the “Orphic" gold tablets', Mouseion 3.6 (2006) 383-98, there is a reference to joy at 397. Finally, for a discussion of the relation between Plato's treatment of pleasure in Timaeus and in the rest of his corpus, $c f$. Wolfsdorf (n.75 2013) 40-102. 